\title{
REGULATING DC LINK VOLTAGE FLUCTUATIONS ON A GRID CONNECTED WAVE POWER SYSTEM USING ENERGY STORAGE
}

\author{
C.E. Jones, S.J. Finney*, C.S. Parry ${ }^{\dagger}$ \\ *University of Strathclyde, Royal College Building, 204 George St, Glasgow, UK, G1 1XW, catherine.jones@eee.strath.ac.uk, \\ ${ }^{+}$Voith Hydro Wavegen Ltd, $13^{a}$ Harbour Road, Inverness, UK, IV1 1SY, colin.parry@wavegen.com
}

Keywords: wave farms, energy storage, power quality, weak networks, wave energy converters

\begin{abstract}
The fluctuating nature of power generated from waves combined with the weak nature of the network, makes the connection of arrays of wave energy converters (WECs) to the network a challenge. This paper investigates the research questions raised by the proposed development of a wave farm using coastal WECs, where the spatial layout of the WECs is restricted and cannot be used to damp the fluctuations in generated power. The concept of using energy storage on a common DC link to compensate for the fluctuations in real power, and ensure that the power quality on a weak, rural distribution network is not compromised, will also be discussed.
\end{abstract}

\section{Introduction}

The Scottish Government aims to generate $2 \mathrm{GW}$ of power in Scotland from wave power by 2020 [15]. In order to achieve this target, it is likely that arrays of wave energy converters (WECs) be connected together to form wave farms, which can then be connected to the grid. The geography of Scotland is such that the areas with the most potential for exploiting the waves are remote, rural areas in the north and west of the country, where the local electrical network is a passive, weak network designed for unidirectional power flow [6, 14].

This paper will consider a 4MW wave farm which is proposed at Siadar, on the Isle of Lewis, the challenges it faces and the research questions which this has raised. It will discuss the concept of using energy storage to ensure that the power quality on the distribution network is not compromised by the presence of a wave farm. It has been noted by previous authors that the integration of WECs to the grid is the final stage in their development and therefore has been researched less than other areas of wave power [11].

Although the research questions presented in this paper have been raised by a particular wave farm development, an overall aim is to develop generic solutions for wave farms consisting of coastal and near shore WECs to enable the full exploitation of Scotland's wave energy resources.
Many of the research questions and problems to be solved specific to the area of wave power arise from the cyclic nature of waves. It is well documented in the literature that waves are complex, consisting of different amplitudes and frequencies [3]. This cyclic nature of the generated power is made even more complex by the constant variation in the amount of power generated by each cycle. The output from a wave farm must be controlled such that the voltage at the point of common coupling to the grid does not go out with the allowed voltage limits set by the distribution network operator (DNO). Excessive variation in the real and reactive power will lead to a power flow which creates variations in grid frequency and voltage out with the acceptable limits. [14].

Fig. 1 shows an example output real power trace from a generator rated at $110 \mathrm{~kW}$ which is driven by a WEC situated on the Isle of Islay. Fig. 2 is a section of the same trace as in Fig 1 , but zoomed in over a period of 250 s to illustrate the high rate of change of real power generated with time and that the power generated with time does not always return to zero in each cycle. By inspection of Fig. 2 it is apparent that one cycle lasts circa $5 \mathrm{~s}$. It is also interesting to note that in some cycles the generator motors for a few seconds, when it will absorb power from the grid. The example trace shown was captured during stormy weather. Stormy conditions are not unusual in the west of Scotland [10] and therefore any wave power system built must be capable of coping with the power fluctuations of the nature shown in Figs. 1 and 2.

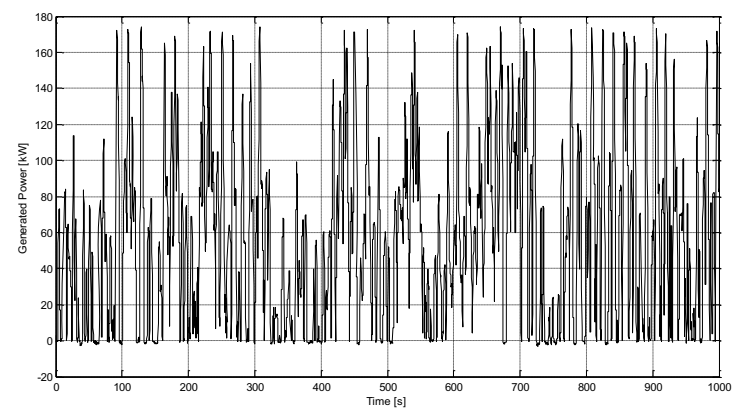

Fig. 1: Example of power generated from $110 \mathrm{~kW}$ WEC device. 


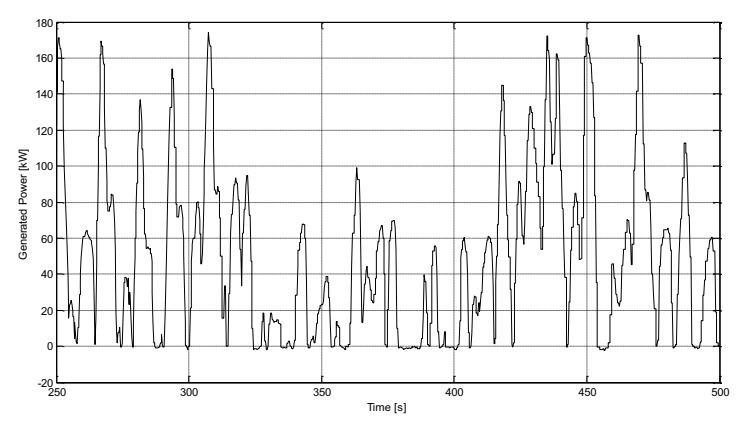

Fig. 2: A section from the same power trace as in Fig.1 to illustrate cyclic nature of the power generated.

This paper aims to raise the research questions which have been brought to the attention of the authors during the initial studies for the Siadar wave farm. These questions centre around how the real power fluctuations shown in Figs 1 and 2 can be prevented from propagating to the local distribution network that a wave farm is connected to.

\section{Power Quality}

As has been identified by previous work on the connection of wave farms to the grid, the major problem to overcome is power quality. This is made clear by inspection of Figs. 1 and 2. Of specific concern is how can the real power fluctuations in the generated power from the individual WEC device generators be controlled such that the quality of power delivered by the wave farm to the grid is acceptable? The fluctuations in the generated power must not be propagated through to the grid. This is particularly important as the local network to which the wave farm is connected is highly likely to be a weak, rural network.

The single line diagram in Fig. 3 highlights the importance of power quality in the case where a wave farm is connected to the distribution network. Fluctuations in the power generated by the wave farm (Pwave) will result in a varying voltage drop across the loads, which will affect the power quality across the network. Therefore it is important that fluctuations in Pwave are not able to propagate through the point of common coupling (PCC) to the loads and grid.

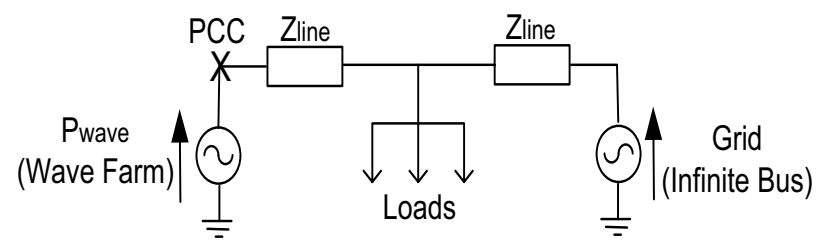

Fig.3: Single Line diagram of a grid connected wave farm.

Ideally, the wave farm should behave as a good citizen to the grid, meaning that it appears as a well behaved aggregate generator [9]. This means that it should have "plug and play" functionality [8], thereby once connected to the grid it will meet the power quality requirements and not have an adverse effect on the local network.

The two main areas of power quality of concern are voltage sags/swells and flicker. Voltage flicker is the variation of the voltage at low frequency, normally between $10-35 \mathrm{~Hz}[1]$. This causes light emitting appliances to flicker at a level visible to the human eye. Flicker is measured according to short term and term flicker, Pst and Plt. Short term flicker is measured over a 10 minute period. Long term flicker is measured over a much longer time scale of hours. A detailed description of flicker and how it can be calculated is given in [1].

The second power quality of importance to wave farms is that of voltage sags and swells. If the rms voltage at the point of common connection between the wave farm and the local network drops below or above a certain percentage of the rated rms voltage, then a voltage sag or swell occurs [7]. The exact voltage limits of a sag or swell depend on the DNO. At the proposed Siadar wave farm, these voltage fluctuations cannot go out with $\pm 3 \%$ of the rated voltage. The severity of the sag or swell depends on the length of time that it lasts for. On a weak network, such sags and swells are particularly problematic because they can lead to flows of excessive reactive power.

\section{Wave Power Technology}

\subsection{Different Types of WEC}

The possible methods to ensure the power quality of the generated power from a wave farm meets is suitable, depends on the type of WEC used by the wave farm. There are two main categories which WEC devices fall into.

\section{Near shore and coastal devices}

\section{Deep water devices.}

Of specific interest to this paper are wave farms which consist of WEC devices which fall into the category of near shore and costal devices. Such devices include the oscillating water column (OWC). Fig. 4 shows a diagram of an OWC. The device works by waves which are incident on the device pushing a column of air up and down through a Wells turbine. A key advantage of the Wells turbine is that its operation is not dependant on the direction of air flow through it. Therefore power is generated both as the air is forced up the column and through the turbine, and as air is forced down the column as the wave retracts, pulling the air back through the turbine. 


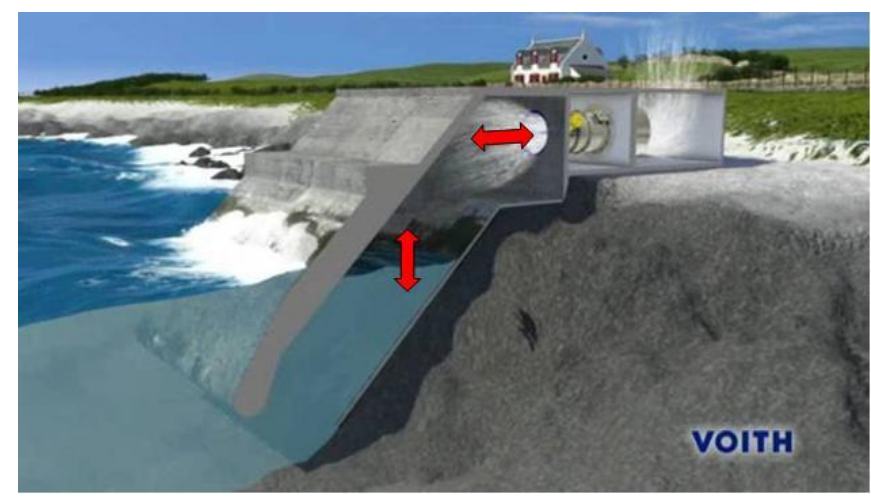

Fig. 4: Oscillating Water Column.

\subsection{Flexibility of Layout of WECs forming a wave farm}

A key difference between the two categories of WEC devices is that there is more flexibility in the physical arrangement of the deep water devices than the devices mounted on the coast. This is important because this flexibility of arrangement for the deep water devices, allows the arrangement of the devices to enable optimal smoothing of the cyclic fluctuations in generated power between devices. In [14] and [6] it is highlighted how the spatial layout of devices can be used to optimise the energy capture and smooth the output power from the wave farm.

However, this high level of flexibility in their physical position to each other is not available to near shore and coastal devices, which are generally restricted in where they can be placed relative to each other. As highlighted in [2] power smoothing by aggregation through spatial positioning of such devices is possible to a small extent, but restrictive.

Near shore and coastal devices are mounted either on the shoreline, or can form part of existing civil engineering installations, such as break waters and harbour walls. This gives such devices an advantage over the deep water devices, because by using existing installations, installation costs are reduced, in addition to the visual environmental impact. As an example, Fig. 5 is an artist's impression of what the 4MW installation at Siadar will look like when complete. An additional advantage of the near shore and coastal WEC devices is that they are easier to access for maintenance.

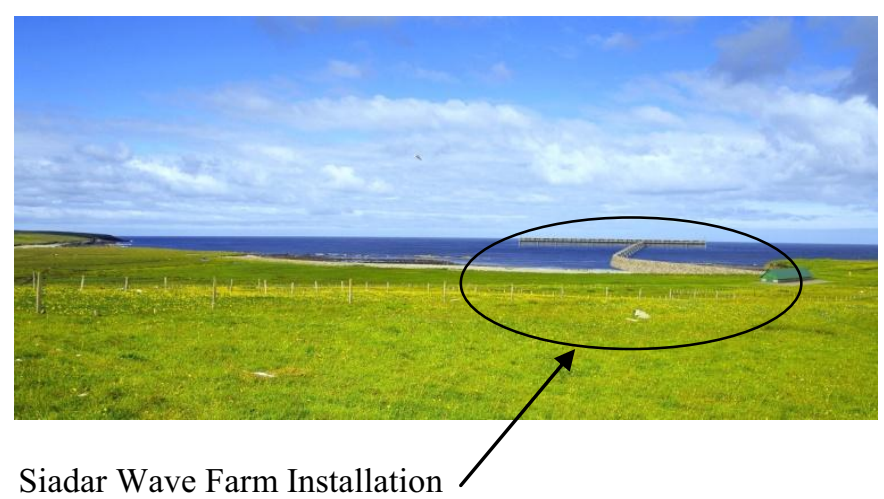

Fig. 5: Artist's impression of the Siadar installation, showing the low visual impact.

\section{Energy Storage to Improve Power Quality}

\subsection{STATCOMs and D-STATCOMs}

As discussed in Section 3, it is unlikely that fluctuations in the generated power from wave farms such as Siadar can be sufficiently smoothed using optimal spacing of the WECs. Therefore the question of how sufficient power smoothing can be achieved remains to be answered.

It has been discussed in the literature in the past that a Distribution-STATCOM (D-STATCOM) or a STATCOM could be used to smooth the output power from a wave farm.

In [11] a STATCOM was proposed as a possible grid interface technology for a single WEC and the grid. In [11] the STATCOM is proposed with energy storage capacity to allow it to compensate for fluctuations in active power, alongside providing reactive power compensation. The research described in [11] indicated that a STATCOM with some energy storage on its DC link will work to smooth fluctuations in generated power, however it is dependent on some energy smoothing taking place during the power take off from the WEC This was possible with the deep water buoy type WEC considered in [11], where the power take off method used a linear direct drive permanent magnet generator. This generator was controlled to damp some of the fluctuations in the power from the waves, and therefore the STATCOM had a secondary role in compensating for fluctuations in the generated power.

The authors in [11] had the flexibility to change the power take off method to enable them to use this to suppress the fluctuations in generated power. At present, linear PMSGs have only been developed for deep water WECs. One option could be to actively control each of the induction generators in an installation such as Siadar. However, these installations will have over 30 generators. Therefore actively controlling each generator is not only costly, but it is potentially very complex and leads to questions about how are the generators co-ordinated and if they need to be co-ordinated? 
A wave farm very similar in location and the same type of WEC used to that proposed for Siadar, is considered in [2]. In [2] the wave farm is interfaced to the grid through a DSTATCOM. The authors of [2] found that the VA rating of the D-STATCOM had to be limited to keep the cost down and therefore some smoothing of the output power had to be carried out by positioning the WEC devices such that they damped each other.

It is discussed in [2] that optimising the placement of the WECs was complicated by a number of factors such as diffraction, sea bed friction and shoaling which are specific to each wave farm site, making it difficult to come up with a generic wave farm layout. As discussed in Section 3, the physical layout of coastal mounted devices is also restricted by the fact that they are mounted to the shore or existing civil engineering constructions, limiting the amount of damping that can be achieved in this way.

The authors in [2] have arrived at a similar conclusion to those in [11]: the success of a STATCOM or D-STATCOM improving power quality in a wave farm relies on some improvement in power quality elsewhere in the system. This leads the authors to consider the possibility of using energy storage on a common DC link between WECs to improve power quality, with no reliance on fluctuation smoothing from the physical layout of the WECs or control of the WEC generators. In addition to enable a STATCOM or DSTATCOM to compensate for fluctuations in real power, some form of energy storage is required. This leads to the question of could energy storage be used on a common DC link to suppress real power fluctuations, removing the need for a STATCOM and simplifying the system?

\subsection{Use of Energy Storage on the DC Link}

The use of energy storage to improve power quality has been investigated in the past in [14] where a large ultra capacitor on the common DC link between several offshore, deep water devices was used to smooth fluctuations in power. However it should be noted that the wave farm discussed in [14] uses deep water WECs and therefore the spatial layout of the devices could be optimised to reduce fluctuations. Therefore the energy storage requirement for the DC link ultra capacitor was reduced.

The concept put forwards by this paper is to investigate if energy storage alone can be used to sufficiently suppress the fluctuations in real power generated by the wave farm WECs?

As shown in Fig, 5, the method proposed is to interface the WECs to a common DC bus. The DC bus includes some energy storage which is controlled to compensate for the fluctuations in generated power and ensure that the fluctuations do not propagate to the grid. The wave farm is interfaced to the grid through a grid connecting inverter. At present the WEC rectifiers are passive. They are regenerative to allow the generators to motor when necessary.

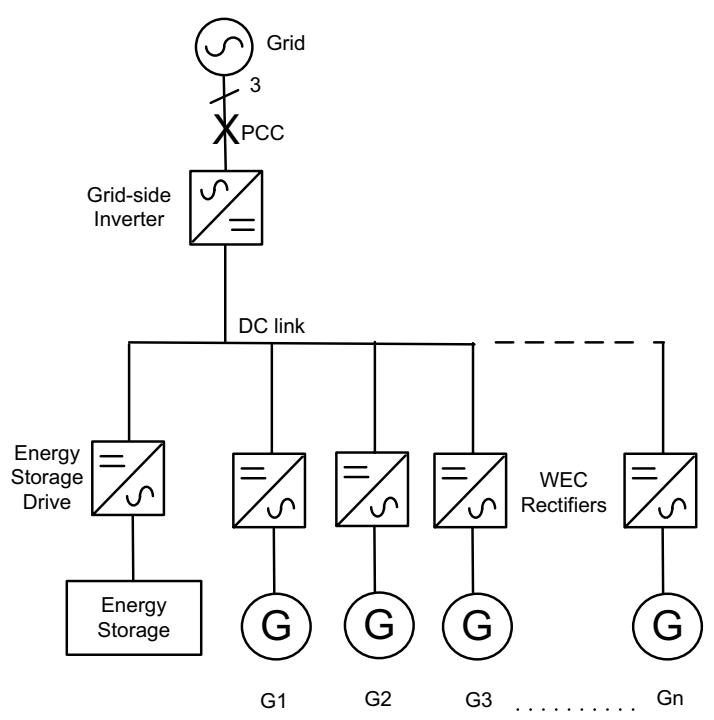

Fig. 5: Diagram showing proposed architecture of wave farm with energy storage on the DC link.

The use of energy storage in combination with a single WEC has been discussed in the literature with offshore devices. In [12] super capacitors are used to smooth the output from a single WEC, which is connected through a back to back rectifier and inverter to the network. The super capacitor is connected to the DC link.

The authors intend to investigate further if energy storage can be used to sufficiently suppress the fluctuations in generated power on the DC link, to prevent them propagating through to the distribution network.

A particularly interesting research question to ask is if the above control and energy storage can be developed to make the wave farm appear as a well behaved wind farm to the local, weak network? If this were possible then can this wave farm perform functions associated with a conventional power plant, such as provide reactive power compensation, frequency and voltage regulation? Large wind farms are expected to be able to withstand disturbances from the grid [4]. If this were possible then technologies and control strategies applied when connecting wind farms to weak networks, can be transferred to wave farms.

It will be necessary to optimise the capacity of the energy storage, such that it is never full, nor empty, but is always able to absorb or inject enough power onto the DC link to ensure that the DC link voltage remains within acceptable limits and that power fluctuations do not propagate through to the grid. This is not a trivial problem to solve because, as illustrated in Figs. 1 and 2, the magnitude of the voltage fluctuations can vary considerably with time.

In addition the most appropriate type of energy storage must be chosen. High speed flywheels are very efficient, but prohibitively expensive. Low speed flywheels are affordable to industry, but have high losses. Other options include super 
capacitors and batteries. Therefore the size, efficiency and cost of the energy storage component and its associated power conversion equipment requires to be optimised.

A co-ordinated control must be developed between the energy storage drive and the grid connection inverter. The grid connection control will regulate the DC link voltage, however the energy storage drive control will inject or absorb power from the DC link based on the DC link voltage level. Therefore the energy storage drive control must be tuned to have a slower response than the grid side inverter control. The importance of co-coordinating the control between these two inverters is demonstrated in [5], where lack of coordination between two inverters, both trying to control a DC link voltage leads to instability in the DC link voltage.

Finally, by considering the concepts presented in [2] and [11], it would be interesting to study the extent that the grid side converter could be used to manage the voltage at the PCC using reactive power compensation. This would require some overrating of the grid-side inverter, requiring optimisation of the rating of the inverter, cost and physical size.

This aspect of the grid-connection of the wave farm is particularly interesting for a connection to a weak grid, as it relies on the network being able to accommodate any fluctuations in reactive power and that real power fluctuations are absorbed without any adverse affect on the power quality.

\section{Conclusions}

This paper has discussed the power quality problems associated with connecting arrays of WEC devices driven by oscillating water columns to form wave farms, which would then be connected to the local network. It has been acknowledged that this local network is very likely to be weak, as the majority of the wave power resource in Scotland is located in areas which are geographically remote and rural.

It has been highlighted that a key advantage of the coastal based WECs is that they can be mounted in existing or planned civil installations, reducing visual environmental impact and maintenance costs compared to deep water WECs. However this also means that there is very limited flexibility in how the devices are physically arranged, reducing the amount by which the devices can interact with each other to damp fluctuations in the amount of power generated.

Therefore methods used to suppress fluctuations in the generated power from WECs are unlikely to work with wave farms of the sort proposed at Siadar. This paper has put forwards the concept of using energy storage alone to suppress the fluctuations in generated power, removing the reliance on the spatial layout of the WECs, and suggested that this could be used to make the wave farm appear as a wind farm to the grid. This would enable the re-use of technology developed for the connection of wind farms to weak networks to be used for wave farms and for a wave farm to act as a model citizen on the distribution network.

\section{Acknowledgements}

The authors wish to thank the SEEKIT RenewNet project for its financial support of the project to date.

\section{References}

1. R. G. Alcorn, W. C. Beattie, "Power Quality Assessment from a Wave Power Station", $16^{\text {th }}$ International Conference and Exhibition on Electricity Distribution, Part 1: Contributions. CIRED, Vol. 4, (2001)

2. M. Barnes, R. El-Feres, S. Kromlides, A. Arulampalam, "Power Quality Improvement for Wave Energy Converters Using a D-STATCOM with Real Energy Storage", International Conference on Power Electronics Systems and Applications, pp. 72-77, (2002)

3. P.R.M. Brooking and M.A. Mueller, "Power conditioning of the output from a linear vernier hybrid permanent magnet generator for use in direct drive wave energy converters", IEE Proceedings -Generation, Transmission and Distribution, Vol. 152, Issue 5, pp. 673-681, (2005)

4. M. F. Farias, P.E. Battaiotto, M.G. Cendoya, "Investigation of UPQC for Sag Compensation in Wind Farms to Weak Grid Connections", IEEE International Conference on Industrial Technology, pp. 937-942, (2010)

5. N. Jayawarna, M. Barnes, C. Jones, N. Jenkins, "Operating Microgrid Energy Storage Control During Network Faults", IEEE International Conference on System of Systems Engineering, pp.1-7, (2007)

6. A. E. Kirpakis, J. Nambiar, D. I. M Forehand and A. R. Wallace, "Modelling Arrays of Wave Energy Converters Connected to Weak Rural Electricity Networks", SUPERGEN '09 International Conference on Sustainable Power Generation and Supply, pp. 1-7, (2009)

7. A. E. Kirpakis and A. R. Wallace, "Maximising energy capture from distributed generators in weak networks", IEE Proceedings -Generation, Transmission and Distribution, Vol. 151, Issue 5, pp. 611-618, (2004)

8. R. H. Lasseter, "Microgrids", IEEE Power Engineering Society Winter Meeting, Vol.1, pp. 305 -308, (2002)

9. R. Lasseter et al, "The CERTS Microgrid Concept", http://www.pserc.wisc.edu/documents/research_documen ts/certs_documents/certs_publications/certs_microgrid, (2002)

10. The Met Office, "Western Scotland: Climate", http://www.metoffice.gov.uk/climate/uk/ws/, (2011)

11. M. Molinas, O. Skjersheim, P. Andreasen, T. Undeland, J. Hals, T. Moan, B. Sorby, "Power electronics as grid interface for actively controlled wave energy converters", International Conference on Clean Electrical Power, pp.188-195, (2007)

12. D.B. Murray, M. G. Egan, J.G. Hayes and D. L. O'Sullivan, "Applications of Supercapacitor Energy 
Storage for a Wave Energy Converter System", $8^{\text {th }}$ European Wave Tidal Energy Conference, pp. 786 -795, (2009)

13. J. Nambiar, A. E. Kirpakis and A. R. Wallace, "Quantification of Voltage Fluctuations Caused by a Wave Farm Connected to Weak, Rural Electricity Networks", $14^{\text {th }}$ International Conference on Harmonics and Quality of Power, pp. 1-8, (2010)

14. M. Rahm et al, Offshore underwater substation for wave energy converter arrays, IET Renewable Power Generation, Vol. 4, Issue 6, pp. 602-612, (2010)

15. The Scottish Government, "Marine Energy Road Map", http://www.scotland.gov.uk/Publications/2009/08/14094 700/12, (2009) 